\title{
«Duty of the fish is revolution»: Karachay-Balkar palindromes
}

\author{
Ali Berberov \\ Gazprom / Saint-Petersburg \\ ali-berberovamail.ru
}

\author{
Liana Berberova \\ Financial University / Moscow \\ berberova. liana@yandex.ru
}

\begin{abstract}
The main idea of the present paper is to uncover the hidden potential of Karachay-Balkar language in Constrained Writing. Being well described and deeply analyzed in terms of major linguistics subdisciplines, Karachay-Balkar language (as well as many other minor languages) lacks academic attention towards creation of experimental forms, e.g., palindromes. The present paper aims to answer the question "How big is the potential of Karachay-Balkar language in creating palindromes of different kinds, and which methods are applicable in doing that?" In order to answer this question, we justify choosing the appropriate lexical databases, and demonstrate that two different approaches are effective: "heuristic method", based on some apriori knowledge about Karachay-Balkar language and our own creativity; and "algorithmic method", based on some set of rules executed on Python. As a result, we have generated many palindromes of different kinds (letter-palindromes, syllable-palindromes, educanto-palindromes, "magic squares"), and about 70 of them are demonstrated in the present paper.
\end{abstract}

Keywords: Karachay-Balkar Language; Palindromes; Constrained Writing; Computational Linguistics; Word Games

DOI: $10.28995 / 2075-7182-2021-20-1021-1030$

\section{«Дело рыбы - революция»: карачаево-балкарские палиндромы}

\author{
Али Берберов \\ ПАО «Газпром» / Санкт-Петербург \\ ali-berberov@mail.ru
}

\author{
Лиана Берберова \\ Финансовый Университет / Москва \\ berberova. liana@yandex.ru
}

\begin{abstract}
Аннотация
Главная идея представленной статьи - обнажить скрытый потенциал карачаево-балкарского языка в комбинаторной литературе. В то время как карачаево-балкарский язык достаточно хорошо изучен и описан в отношении основных разделов лингвистики, он (как и многие другие малые языки) обделен вниманием научного сообщества к экспериментальным языковым формам, в частности, к палиндромам. Наше исследование призвано ответить на вопрос «Каков потенциал карачаево-балкарского языка в создании различных видов палиндромов, и какие методы применимы для этого?» Для ответа на этот вопрос мы обосновываем выбор соответствующих лексических баз и демонстрируем, что два подхода доказывают свою эффективность: «эвристический метод», основанный на априорном знании о карачаево-балкарском языке и собственном творческом начале, и «алгоритмический метод», основанный на наборе правил, исполняемых на языке Python. В результате нами получено большое количество палиндромов разных видов (буквенные, слоговые, заумные, «магические квадраты»), из которых около 70 представлено в данной статье.

Ключевые слова: карачаево-балкарский язык; палиндромы; комбинаторная литература; компьютерная лингвистика; игра слов
\end{abstract}

\section{1 Введение}

При достаточно широком охвате и глубоком анализе основных разделов карачаево-балкарского языкознания [3], на наш взгляд, незаслуженно мало внимания уделяется его игровым, экспериментальным формам. В частности, нам не известно ни одной научной работы, посвященной потенциалу использования карачаево-балкарского языка в комбинаторной литературе. Под комбинаторной литературой мы понимаем литературу, создаваемую в соответствии с формальными ограничениями. Обзор такой литературы на русском и других европейских языках представлен в книге Т.Б. Бонч-Осмоловской «Введение в литературу формальных ограничений» [1]. Можно 
заметить, что, зародившись еще в античности (Симмий Родосский, Ликофрон), традиция комбинаторной литературы проявилась в самых разнообразных жанрах, и наибольшее развитие получила в русском, английском и французском языках. При этом нам известен лишь один автор палиндромов на карачаево-балкарском языке - поэт Билал Лайпанов [11]. Надеемся, что наша исследовательская работа пробудит интерес к заявленной проблематике и позволит в будущем расширить список примеров успешной генерации комбинаторных текстов на карачаево-балкарском языке.

Заметим, что обзор статей, опубликованных по материалам международной конференции по компьютерной лингвистике и интеллектуальным технологиям «DIALOGUE» за период 20002020 гг. демонстрирует неожиданное отсутствие исследований по комбинаторной литературе. Этот факт подкрепляет нашу уверенность в новизне и актуальности заявленной темы.

\section{2 Цели, задачи, методы}

Вслед за Т.Б. Бонч-Осмоловской [6] в настоящей работе и в последующих работах цикла мы будем рассматривать «комбинаторную литературу» как литературные произведения, образованные на основе формального комбинирования определенных элементов текста. Понятия «литература формальных ограничений», «потенциальная литература», «литература технэ» мы считаем синонимичными понятию «комбинаторная литература», но именно «комбинаторной литературе» отдаем приоритет в употреблении.

Целью нашего цикла исследований является установление потенциала карачаево-балкарского языка в каждом отдельном поджанре комбинаторной литературы. В данном конкретном исследовании в качестве отправной точки выбран «палиндром». Причина такого выбора состоит в том, что, на наш взгляд, именно палиндром является своеобразной «визитной карточкой» комбинаторной литературы, поскольку обладает следующими характеристиками:

- широко представлен в огромном количестве языков и эпох;

- подразделяется на большое количество поджанров, отличающихся логикой построения и длиной;

- хорошо известен не только специалистам, но и широкой публике (вспомним, например, фильм 2020 года «Довод»).

Для достижения поставленной цели мы планируем решить ряд задач, в частности:

- идентификация лексической базы, используемой в генерации палиндромов;

- выбор анализируемых поджанров палиндрома;

- генерация искомых палиндромов.

Для генерации палиндромов мы планируем применять следующие методы (совместно или раздельно):

- $\quad$ эвристические - использование авторами собственного творческого начала, подкрепленного априорными знаниями о словообразовании в карачаево-балкарском языке;

- $\quad$ алгоритмические - использование авторских программ на языке Python, генерирующих образцы соответствующих поджанров палиндромов.

\section{3 Идентификация лексической базы}

В качестве лексической базы для исследования нами используются два словаря - условно «малый» и «большой».

«Малый» словарь получен на базе электронного словаря на сайте Фонда «Эльбрусоид» [9]. Этот словарь представляет собой результат оцифровки карачаево-балкарского словаря под редакцией Э.Р. Тенишева и Х.И. Суюнчева, изданного в 1989 году [5]. Естественно, все слова в этом словаре представлены в своих начальных формах. Количество таких слов составило 32232.

«Большой» словарь призван дополнительно учесть все словообразовательные и словоизменительные варианты. Так как такого готового решения нам не удалось найти, мы написали код, призванный вычленить все возможные словоформы из возможно большого массива текстов на 
карачаево-балкарском языке. В качестве такого массива мы использовали выборку из коллекции художественных текстов, опубликованной на сайте Фонда «Эльбрусоид» [10]. Из такой коллекции текстов были удалены файлы на русском языке, а остальные были преобразованы в формат txt. Bсе такие текстовые файлы были обработаны для получения множества уникальных словоформ, количество которых составило 161959.

В дальнейшем мы будем считать, что «малый» словарь - это словарь лемм, а «большой» словарь - это словарь токенов. Отметим, что «большой» словарь содержит значительное количество слов с опечатками ввиду несовершенства процессов сканирования документов и их последующего распознавания. Однако для целей генерации палиндромов это не критично, так как все генерируемые структуры подвергаются авторской постмодерации.

Заметим, что процесс формирования «большого» словаря тесно связан с корпусной лингвистикой - еще одним направлением лингвистики, не нашедшим пока должного освещения в карачаево-балкарском языкознании.

\section{4 Выбор поджанров палиндрома}

Как указывалось ранее, палиндромы различаются по своей логике построения и длине. Так, если назвать «элементарной единицей» часть текста, которая не меняет направления своего прочтения независимо от направления прочтения самого текста, можно рассматривать следующую классификацию палиндромов:

\begin{tabular}{|c|c|c|}
\hline $\begin{array}{l}\text { Элементарная } \\
\text { единица }\end{array}$ & Описание палиндрома & $\begin{array}{l}\text { Пример палиндрома } \\
\text { на русском языке }\end{array}$ \\
\hline Буква & $\begin{array}{l}\text { Канонический вид палиндрома: прямое прочте- } \\
\text { ние текста по буквам совпадает с его обратным } \\
\text { прочтением по буквам }\end{array}$ & (1) Казак \\
\hline Слог & $\begin{array}{l}\text { Прямое прочтение текста по слогам совпадает с } \\
\text { его обратным прочтением по слогам }\end{array}$ & (2) По следу иду слепо \\
\hline Слово & $\begin{array}{l}\text { Прямое прочтение текста по словам совпадает с } \\
\text { его обратным прочтением по словам }\end{array}$ & $\begin{array}{l}\text { (3) Олово стало золото } \\
\text { - золото стало олово }\end{array}$ \\
\hline
\end{tabular}

Таблица 1: Условная классификация палиндромов

Т.Б. Бонч-Осмоловская в [1] анализирует палиндромы с элементарными единицами и более высокого порядка (например, строчные палиндромы), однако для целей нашей работы мы ограничимся только буквенными и слоговыми палиндромами (отметим, что они могут представлять собой как слова, так и предложения).

Кроме того, будет осуществлен поиск палиндромных пар слов. В таких парах обратное побуквенное прочтение одного слова образует новое слово (по сути это частный случай анаграммы). Почти наверняка такая пара слов не будет представлять собой осмысленной фразы, но такие пары могут оказаться весьма полезны для создания полноценных палиндромных предложений.

Добавим сюда же такой поджанр палиндромов как «магические квадраты», самый известный пример которых приведен ниже:

(4) \begin{tabular}{|l|l|l|l|l|}
\hline$S$ & $A$ & $T$ & $O$ & $R$ \\
\hline$A$ & $R$ & $E$ & $P$ & $O$ \\
\hline$T$ & $E$ & $N$ & $E$ & $T$ \\
\hline$O$ & $P$ & $E$ & $R$ & $A$ \\
\hline$R$ & $O$ & $T$ & $A$ & $S$ \\
\hline
\end{tabular}

В этом древнем образце магического квадрата размером $5 \times 5$ записаны 5 латинских слов, которые можно прочитать и слева направо, и справа налево, и сверху вниз, и снизу вверх. Особенность именно этого квадрата еще и в том, что прочитанные подряд слова образуют достаточно осмысленную фразу: «Сеятель Арепо управляет плугом (колёсами)». 
И наконец будут рассмотрены так называемые палиндромы с заумью, блестящие примеры которых были некогда предложены Германом Лукомниковым [2]:

$$
\text { (5) «ПЛАНЫ ПАРТИИ - ИИТРАП ЫНАЛП!» }
$$

(6) «отяа какая-то»

Нам не известны устоявшиеся определения палиндромов с заумью, но можно сказать, что их ключевой характеристикой является намерение автора посмеяться над собой и над концепцией палиндрома как такового.

Упомянем также о так называемых «белых палиндромах» - это фразы, которые по угловатости своего звучания напоминают традиционные палиндромы, однако на поверку оказываются абсолютно лишены палиндромных свойств. Такой «хулиганский» поджанр не рассматривается нами, поскольку он требует существования в языке некой традиции звучания палиндромов, а такая традиция в карачаево-балкарском языке отсутствует.

\section{5 Генерация палиндромов}

В данном разделе представлены результаты генерации палиндромов разных поджанров. Заметим, что в карачаево-балкарском алфавите присутствует диграфы «гъ», «дж», «къ», «нг», каждый из которых следует рассматривать как одну букву (а не две буквы).

\section{1 Генерация палиндромных слов (пар слов) с побуквенным прочтением}

Палиндромные слова и пары слов генерировались нами отдельно как на основе малого словаря, так и на основе большого словаря (который приоритетен ввиду большего размера и наличия в нем редких слов, не встречающихся в словарях), и ранжировались по длине.

На базе малого словаря получены:

- одно 6-буквенное слово (7) «къуллукъ» («служба») и много 5-буквенных;

- одна 6-буквенная пара (8) «къашпакъ - къапшакъ» (оба слова означают «хлев», различие в написании связано с метатезой) и много 5-буквенных.

На базе большого словаря получены результаты, сведенные в таблицы 2 и 3:

\begin{tabular}{|l|l|l|}
\hline № & \multicolumn{1}{|c|}{ Оригинал } & \multicolumn{1}{c|}{ Перевод } \\
\hline 1 & (9) кесек-кесек & по чуть-чуть \\
\hline 2 & $(10)$ къурутурукъ & искоренит \\
\hline 3 & $(11)$ исси-исси & горячо-горячо \\
\hline 4 & $(12)$ къараракъ & черноватый \\
\hline 5 & $(13)$ ачьгъыча & в открытую \\
\hline 6 & $(14)$ угужугу & помятый (о шерсти) \\
\hline 7 & $(15)$ азая-аза & сокращаясь \\
\hline 8 & $(16)$ умутуму & мою мечту \\
\hline 9 & $(17)$ алашала & низкорослые \\
\hline 10 & $(18)$ къурурукъ & установит / исчезнет \\
\hline 11 & $(19)$ игилиги & его благо \\
\hline
\end{tabular}

Таблица 2: Самые длинные палиндромные слова

\begin{tabular}{|c|c|c|}
\hline № & Оригинал & Перевод \\
\hline 1 & (20) къыральынга - ангыларыкъ & твоей стране - поймет \\
\hline 2 & (21) балькъвны - ынкъьлаб & рыбу - революция \\
\hline 3 & (22) кийерик-кирейик & наденет - зайдем же \\
\hline 4 & (23) амальнга - ангылама & по твоей возможности - не пойми \\
\hline 5 & (24) альлкъьлна - аньлкъылла & все еще - принадлежащие ему \\
\hline 6 & (25) къылллача - ачаллькь & как струны - сможет открыть \\
\hline 7 & (26) къарыбат - табыракъ & [некий топоним] - получше \\
\hline 8 & (27) къылыцила - алчыльыкъ & сабли - первенство \\
\hline 9 & (28) къырыббыз - зыббырыкъ & наша равнина - расстройство желудка \\
\hline
\end{tabular}

Таблица 3: Самые длинные палиндромные пары слов 


\section{2 Генерация палиндромных слов с послоговым прочтением}

Послоговый подход к генерации палиндромов осложнен неоднозначностью правил членения слова на слоги в карачаево-балкарском языке, и как следствие, трудностью программной реализации такой генерации. По этой причине для послоговой генерации палиндромных слов мы преимущественно использовали эвристический подход, основанный на предпосылке, что большая часть карачаево-балкарских корней состоит из одного или двух слогов, и дальнейшее удлинение слова связано со словообразовательными и словоизменительными аффиксами (каждый из которых в большинстве случаев состоит из одного слога).

Таким образом, задача нахождения длинных слоговых палиндромов сводится к сопоставлению множества слогов, составляющих карачаево-балкарские аффиксы, с множеством слогов, которые могут встречаться в карачаево-балкарских корнях.

Трехслоговые палиндромы встречаются очень часто и не составляют труда для генерации. Простой способ их нахождения состоит в том, что надо задаться определенным однослоговым аффиксом и применить его к двухслоговому корню, первый слог которого совпадает со слогом аффикса.

Приведем ряд таких примеров: (29) «сабырса» - «ты спокоен»; (30) «макъама» - «я - лягушка»; (31) «дырындыь» - «это - скошенная трава».

Нас же интересуют более длинные образцы, нахождение которых осложняется:

- проблемой сочетаемости двух аффиксов - далеко не каждые два аффикса могут быть спарены;

- специфичностью карачаево-балкарских корней - крайне мало корней начинаются, например, на буквы «гъ», «Л», «р», которые при этом весьма характерны для аффиксов.

Тем не менее нам удалось обнаружить 11 кандидатов на звание самого длинного слогового палиндрома (все состоят из 5 слогов). Большинство из них маловероятно встретить в разговорной речи или художественной литературе. Однако, на наш взгляд, они не противоречат законам карачаево-балкарского словообразования.

\begin{tabular}{|c|c|c|c|}
\hline № & Оригинал & Перевод & Комментарий \\
\hline 1 & (32) магъанагъама & я - к смыслу & \multirow{2}{*}{ Вероятно два наиболее адекватных варианта } \\
\hline 2 & (33) мадарындама & я - в его возможности & \\
\hline 3 & (34) мачукъачума & $\begin{array}{l}\text { я - стрелок из "ма- } \\
\text { чукъа" }\end{array}$ & $\begin{array}{l}\text { «Мачукъа» - это вид ружья. Использован аф- } \\
\text { фикс существительных со значением рода дея- } \\
\text { тельности «-чу». Однако правомерность его } \\
\text { использования вместо его фонетического вари- } \\
\text { анта «-чы» остается под вопросом }\end{array}$ \\
\hline 4 & (35) мегеджингеме & я - к свиноматке & $\begin{array}{l}\text { «Мегеджин» - балкарский вариант карачаев- } \\
\text { ского слова «бегеджен» }\end{array}$ \\
\hline 5 & (36) меникиниме & $\begin{array}{l}\text { я [принадлежу] моему } \\
\text { [чему-то] }\end{array}$ & Труднопредставимый образ \\
\hline 6 & (37) сагъайыугъаса & ты - к пробуждению & \multirow{3}{*}{$\begin{array}{l}\text { Грамматически верные, но не очень продук- } \\
\text { тивные словоформы }\end{array}$} \\
\hline 7 & (38) садакъадаса & ты - в милостыни & \\
\hline 8 & (39) санамынаса & ты - к его счету & \\
\hline 9 & (40) санатынаса & ты - к его сенату & Использовано устаревшее слово «санат» \\
\hline 10 & (41) салыныуллыса & $\begin{array}{l}\text { ты - тот, кого можно } \\
\text { устроить [на работу] }\end{array}$ & \multirow{2}{*}{$\begin{array}{l}\text { Использован аффикс прилагательных «-лы». } \\
\text { Однако правомерность его использования вме- } \\
\text { сто его фонетического варианта «-лу» остается } \\
\text { под вопросом }\end{array}$} \\
\hline 11 & (42) салышыуллыса & ты - скандальный & \\
\hline
\end{tabular}

Таблица 4: Слоговые палиндромы

На основе составленной таблицы можно сделать занятный предварительный вывод, что для образования 5-слоговых палиндромов из всего многообразия карачаево-балкарских аффиксов только аффиксы сказуемости 1 и 2 лица единственного числа «-ма», «-ме», «-са» могут одновременно завершать слово и совпадать по написанию с первым слогом корня. Подчеркнем, однако, что все эти слоговые палиндромы получены с преимущественным использованием 
эвристического метода, а не алгоритмического. Поэтому мы допускаем, что алгоритмизация поставленной задачи и ее компьютерная реализация могут существенно дополнить представленный список и возможно даже включить в него слоговые палиндромы, содержащие более 5 слогов.

\section{3 Генерация палиндромных предложений с побуквенным прочтением}

В отличие от достаточно легко алгоритмизируемого поиска палиндромных слов, поиск палиндромных предложений представляет собой крайне нетривиальную задачу. Карачаево-балкарский же язык (как и большинство других известных нам языков) предъявляет определенные требования к сочетаемости слов в предложении. Возможно бурное развитие NLP (natural language processing = обработка естественного языка) в скором времени и позволит нам отдать компьютеру на откуп генерацию палиндромных предложений. Однако на текущем этапе для решения заявленной задачи мы не можем обойтись без эвристических методов (отметим при этом хорошее подспорье в виде продемонстрированных ранее палиндромных пар слов).

Ниже представлен ряд обнаруженных нами палиндромных предложений ${ }^{1}$. Отдельно отметим историю обнаружения первых трех примеров: мы отталкивались от предположения, что известные палиндромы на других тюркских языках могут сохранить свое свойство при переводе на карачаево-балкарский язык. Обзор статьи «Палиндром» в Википедии на разных тюркских языках показал, что только на турецкой странице представлен обширный набор качественных палиндромных предложений (в количестве 62 примеров [12]). Перевод всех этих предложений на карачаево-балкарский язык привел к потере палиндромичности каждого из них, за исключением одного - под номером 1.

Палиндромы №2 и 3 аналогичным образом получены с сайта письменного корпуса татарского языка [8]. Опять же мы наблюдаем низкую «приживаемость» иноязычных палиндромов: из 41 опубликованного татарского палиндрома лишь 2 не потеряли своей палиндромичности при переводе на карачаево-балкарский язык.

Остальные примеры - авторские: №4-7 придуманы «с нуля», остальные представляют собой попытки «скрестить» столбцы «Оригинал» из таблиц 2 и 3 (таких попыток очевидно было $9 \times 11 \times 2=198$, но как мы убедимся, лишь малая часть из получившихся словосочетаний может быть признана осмысленными палиндромами).

\begin{tabular}{|c|c|c|}
\hline № & Оригинал & Перевод \\
\hline 1 & (43) Не манга сен, не санга мен & Что ты для меня, что я для тебя \\
\hline 2 & (44) Таш ашат & Накорми камнем \\
\hline 3 & (45) Am ашата & Кормя лошадь \\
\hline 4 & (46) Ал буну исси уну бла & Возьми это с его горячей мукой \\
\hline 5 & (47) Агъач кибик чагъа & Расцветая как лес \\
\hline 6 & (48) Бычакъ кибик къачыб & Убежав как нож \\
\hline 7 & (49) Адам, таб умутуму, батма да & Человек, найди мою мечту, да не утони \\
\hline 8 & (50) Къыралынг а кесек-кесек ангыларыкъ & А страна твоя по чуть-чуть поймет \\
\hline 9 & (51) Къыралынг а умутуму ангыларыкъ & А страна твоя поймет мою мечту \\
\hline 10 & (52) Балыкъвы къурутурукъ ынккъылаб & Революция, которая уничтожит рыбу \\
\hline 11 & (53) Къылычлла къурутурукъ алчылыкъ & Первенство в уничтожении мечей \\
\hline 12 & (54) Зыбырыкъ къурутурукъ къырыбыз & $\begin{array}{l}\text { Наша равнина, которая искоренит расстрой- } \\
\text { ство желудка }\end{array}$ \\
\hline 13 & (55) Амалынга умутуму ангылама & По возможности не пойми мою мечту \\
\hline 14 & (56) Алчылылькъ къурурукъ къылылычла & Мечи, которые установят первенство \\
\hline 15 & (57) Балыкъны иши - ынкъыллаб & Дело рыбы - революция \\
\hline
\end{tabular}

Таблица 5: Палиндромные предложения

Таков предварительный итог формирования базы карачаево-балкарских палиндромных предложений. Любой желающий может внести свою лепту, проанализировав таблицы выше: уверены, на их основе можно придумать новые, возможно более длинные палиндромы.

\footnotetext{
${ }^{1}$ Ввиду требований к формату и объему изложения мы намеренно не приводим примеры палиндромов из стихотворений Билала Лайпанова «Палиндром назмула», с которыми можно ознакомиться в [11].
} 


\section{4 Генерация магических квадратов}

Наше знакомство с представленным выше магическим квадратом $5 \times 5$ на латинском языке сподвигло нас на поиски аналогичных квадратов на карачаево-балкарском языке. С помощью соответствующего кода на языке Python была проверена возможность генерации магических квадратов размерами $4 \times 4,5 \times 5,6 \times 6,7 \times 7$.

В результате установлена невозможность существования магических квадратов размерами $6 \times 6$ и 7×7 (и почти наверняка любых квадратов большего размера).

В отношении же квадратов размерами $4 \times 4$ и $5 \times 5$ программа выдала несколько весьма занимательных образцов:

$(58)$

\begin{tabular}{|l|l|l|l|l|}
\hline $\boldsymbol{M}$ & $a$ & $p$ & $m$ & март \\
\hline$a$ & $\partial ж$ & $a$ & $p$ & аджарский \\
\hline$p$ & $a$ & дж & $a$ & раджа \\
\hline$m$ & $p$ & $a$ & м & червонный \\
\hline
\end{tabular}

\begin{tabular}{l|l|l|l|l|}
\hline \multicolumn{5}{l|}{$(59)$} \\
\hline$\kappa b$ & $y$ & $y$ & $a$ & красно-желтый / гоняя \\
\hline$y$ & $y$ & $\pi$ & $y$ & ядовитый \\
\hline$y$ & $\pi$ & $y$ & $y$ & вой \\
\hline$a$ & $y$ & $y$ & $\kappa b$ & время / пора \\
\hline
\end{tabular}

\begin{tabular}{l|l|l|l|l|}
\hline \multicolumn{5}{l|}{$(60)$} \\
\hline$\kappa b$ & $y$ & $y$ & $a$ & красно-желтый / гоняя \\
\hline$y$ & $y$ & $u$ & $y$ & охотник \\
\hline$y$ & $u$ & $y$ & $y$ & полет \\
\hline$a$ & $y$ & $y$ & $\kappa b$ & время / пора \\
\hline
\end{tabular}

(61)

\begin{tabular}{|l|l|l|l|l|}
\hline$a$ & $p$ & $a$ & $\kappa b$ & скирда \\
\hline$p$ & $a$ & дж & $a$ & раджа \\
\hline$a$ & дж & $a$ & $p$ & аджарский \\
\hline$\kappa b$ & $a$ & $p$ & $a$ & черный \\
\hline
\end{tabular}

$$
\text { (62) }
$$

\begin{tabular}{|l|l|l|l|l|}
\hline$y$ & $y$ & $y$ & $ч$ & горсть \\
\hline$y$ & $y$ & $\pi$ & $y$ & ядовитый \\
\hline$y$ & $\pi$ & $y$ & $y$ & вой \\
\hline$y$ & $y$ & $y$ & $y$ & молва [о нем] \\
\hline
\end{tabular}

$$
\text { (63) }
$$

\begin{tabular}{|l|l|l|l|l|}
\hline$y$ & $y$ & $y$ & $u$ & горсть \\
\hline$y$ & $y$ & $u$ & $y$ & охотник \\
\hline$y$ & $u$ & $y$ & $y$ & полет \\
\hline$y$ & $y$ & $y$ & $y$ & молва [о нем] \\
\hline
\end{tabular}

Таблица 6: Магические квадраты 4x4

(64)

\begin{tabular}{|c|c|c|c|c|l|}
\hline 3 & $a$ & $M$ & $a$ & $H$ & время \\
\hline$a$ & $c$ & $b l$ & $p$ & $a$ & сбереги \\
\hline $\mathcal{M}$ & $b l$ & $\check{u}$ & $b l$ & $\mathcal{M}$ & мой мозг \\
\hline$a$ & $p$ & $b l$ & $c$ & $a$ & если устанет / ты туда \\
\hline$H$ & $a$ & $M$ & $a$ & 3 & намаз \\
\hline
\end{tabular}

(65)

\begin{tabular}{|c|c|c|c|c|l|}
\hline 3 & $a$ & $M$ & $a$ & $H$ & время \\
\hline$a$ & $u$ & $b l$ & $m$ & $a$ & причиняя боль \\
\hline$M$ & $b l$ & $\check{u}$ & $b l$ & $M$ & мой мозг \\
\hline$a$ & $m$ & $b l$ & $u$ & $a$ & как [его] имя / как [его] лошадь \\
\hline$H$ & $a$ & $M$ & $a$ & 3 & намаз \\
\hline
\end{tabular}

(66)
\begin{tabular}{|c|c|c|c|c|l|}
\hline$c$ & $b l$ & $M$ & $a$ & $H$ & подобный \\
\hline$b l$ & $u$ & $b l$ & $\pi$ & $a$ & протираясь \\
\hline$M$ & $b l$ & $\check{u}$ & $b l$ & $M$ & мой мозг \\
\hline$a$ & $\pi$ & $b l$ & $u$ & $b l$ & [его] купля \\
\hline$H$ & $a$ & $M$ & $b l$ & $c$ & честь \\
\hline
\end{tabular}

Таблица 7: Магические квадраты 5х5

Отметим ряд особенностей полученных квадратов:

1. Обращение квадрата относительно вертикальной или горизонтальной центральной оси приводит к получению нового квадрата (с теми же словами в обратном порядке).

2. Некоторые слова неожиданно часто встречаются в разных квадратах одного размера. Самый показательный пример - слово «мыйым»: оно не является единственным в карачаевобалкарском языке пятибуквенным палиндромом, но только оно способно образовывать магические квадраты $5 \times 5$. 
3. У квадрата [«уууч»; «уучу»; «учуу»; «чууу»] две особенности:

- во-первых, это единственный «бинарный» квадрат (в нем используются только две буквы аналогично «0» и «1» из двоичного кода);

- во-вторых, в отличие от других квадратов $4 \times 4$, этот квадрат может быть осмыслен с существующими словоформами (и переведен как «Молва о полете охотника за горстью»). Это предположение, однако, требует дополнительного подтверждения специалистов в карачаево-балкарской филологии.

4. Среди квадратов $5 \times 5$ осмысленностью, на наш взгляд, обладает самый первый квадрат, который может быть переведен как «Сбереги время. Если устанет мой мозг - намаз».

\section{5 Генерация палиндромов с заумью}

В завершение приведем полушутливые авторские примеры палиндромов с заумью: каждый пример - это вымышленный диалог, где реплика одного собеседника призвана дополнить реплику второго собеседника до палиндрома, а реплика второго собеседника обеспечивает необходимый контекст. Уверены, что читатели при желании могут качественно расширить этот список.

\begin{tabular}{|c|c|c|}
\hline № & Оригинал & Перевод (с сохранением палиндромичности) \\
\hline 1 & $\begin{array}{l}\text { (67) - Атынг къалайды? } \\
\text { - Дйалакъ Нгыта }\end{array}$ & $\begin{array}{l}\text { - Как тебя зовут? } \\
\text { - Туво Зябеткак }\end{array}$ \\
\hline 2 & $\begin{array}{l}\text { - Амашнаж льммылых! } \\
\text { - Хылымылыл жаншама! }\end{array}$ & $\begin{array}{l}\text { - Ихупе чиро воген! } \\
\text { - Не говори чепухи! }\end{array}$ \\
\hline 3 & $\begin{array}{l}\text { - Пароль сёзюнг неди? } \\
\text { - «Иденнгюзёсьлорап» }\end{array}$ & $\begin{array}{l}\text { - Какой твой пароль? } \\
\text { - «Блорапйовтйокак» }\end{array}$ \\
\hline
\end{tabular}

Таблица 8: Палиндромы с заумью

\section{6 Выводы}

Заключение о применимости методов генерации палиндромов для карачаево-балкарского языка и (предположительно) для некоторых других языков представлено в виде таблицы:

\begin{tabular}{|c|c|c|c|}
\hline № & $\begin{array}{c}\text { Поджанры } \\
\text { палиндромов }\end{array}$ & $\begin{array}{c}\text { Методы генерации для } \\
\text { карачаево-балкарского языка }\end{array}$ & $\begin{array}{l}\text { Методы генерации для } \\
\text { других языков }^{2}\end{array}$ \\
\hline 1 & \begin{tabular}{lr}
\multicolumn{2}{l}{ Палиндромные } \\
слова $\quad$ (пары \\
слов) с побук- \\
венным про- \\
чтением
\end{tabular} & $\begin{array}{l}\text { Применим и эвристический метод, } \\
\text { но алгоритмический гораздо более } \\
\text { продуктивен }\end{array}$ & $\begin{array}{l}\text { Применим и эвристический метод, } \\
\text { но алгоритмический гораздо более } \\
\text { продуктивен }\end{array}$ \\
\hline 2 & $\begin{array}{l}\text { Палиндромные } \\
\text { слова с посло- } \\
\text { говым прочте- } \\
\text { нием }\end{array}$ & $\begin{array}{l}\text { Целесообразно совместное приме- } \\
\text { нение эвристического и алгорит- } \\
\text { мического метода }\end{array}$ & $\begin{array}{l}\text { В случае наличия в языке одно- } \\
\text { значных правил послогового чле- } \\
\text { нения слов целесообразно исполь- } \\
\text { зование алгоритмического метода }\end{array}$ \\
\hline 3 & $\begin{array}{l}\text { Палиндромные } \\
\text { предложения }\end{array}$ & $\begin{array}{l}\text { Целесообразно совместное приме- } \\
\text { нение эвристического и алгорит- } \\
\text { мического метода }\end{array}$ & $\begin{array}{l}\text { Применимость методов зависит от } \\
\text { типов морфологической и синтак- } \\
\text { сической структуры языка }\end{array}$ \\
\hline 4 & $\begin{array}{l}\text { Магические } \\
\text { квадраты }\end{array}$ & $\begin{array}{l}\text { Практически реализуем только ал- } \\
\text { горитмический метод }\end{array}$ & $\begin{array}{l}\text { Практически реализуем только ал- } \\
\text { горитмический метод }\end{array}$ \\
\hline 5 & $\begin{array}{l}\text { Палиндромы с } \\
\text { заумью }\end{array}$ & $\begin{array}{l}\text { Предпочтителен } \\
\text { метод }\end{array}$ & $\begin{array}{l}\text { Предпочтителен } \\
\text { метод }\end{array}$ \\
\hline
\end{tabular}

Таблица 9: Методы генерации для различных поджанров палиндромов

\footnotetext{
${ }^{2}$ Применимость методов генерации палиндромов для других языков указана на основе имеющихся авторских предположений и исключительно для языков, использующих кириллицу или латиницу.
} 
Продуктивность проведенного нами исследования позволяет сделать вывод о низком пороге вхождения в «мир палиндромов» (по крайней мере, для языков, использующих кириллицу или латиницу). Действительно, программная составляющая работы представляет собой простейший код на языке Pуthon без использования каких бы то ни было дополнительных библиотек. В случае палиндромных слов и пар слов используется посимвольное сравнение токенов из словарей, с последующим ранжированием результатов по длине при необходимости; в случае магических квадратов используется чуть больше строк кода в соответствии с [7].

\section{7 Заключение}

Результативность использованных нами методов позволяет предположить, что целесообразно ввести в карачаево-балкарское языкознание новый термин для обозначения слова «палиндром». В качестве таких претендентов мы предлагаем два слова:

1. Кюзгюлюк. В этом слове аффикс «-люк», выражающий значение отвлеченности, присоединен к корню «кюзгю» («зеркало»). Выбор этого корня обусловлен достаточно близкой ассоциативной связью между «зеркалом» и «палиндромом». Так, Т. Б. Бонч-Осмоловская замечает: «палиндром, изменяя порядок прочтения букв фразы, ставит зеркало на траектории чтения, запуская процесс обратного хода времени. Отраженный от зеркала, симметричный стих преобразует не только пространство записи, но и временной порядок прочтения» [1]. В словаре [5] слово «кюзгюлюк» отсутствует, однако оно встречается как минимум единожды в стихотворении Кулиева Хажимусы «Сюеме» в строчке «Кюзгюлюк этген таза кёллерин» [4], которую можно перевести как «[Её] чистые озера, создающие зеркальность».

2. Кюлюшюлюк. В основе этого слова лежит заманчивая идея использовать для обозначения термина «палиндром» слово, которое само будет палиндромом (насколько мы знаем, это будет беспрецедентно для мировых языков). Жесткие законы карачаево-балкарского словообразования накладывают ряд ограничений: в частности, нам хотелось сохранить аффикс отвлеченности («люк», «-лыкъ», «-лукъ»), что крайне сильно сужает выбор возможных корней. Предлагаемое слово «кюлюшюлюк» не встречается ни в известных нам словарях тюркских языков, ни в карачаево-балкарской художественной литературе, однако не вызывает фонетического «отторжения» и семантически связано с глаголом «кюлюшюрге» - смеяться, хохотать (всем вместе), что удачно отражает игровую природу палиндрома.

По итогам проведенной работы можно сделать вывод, что карачаево-балкарский язык обладает большим потенциалом в генерировании палиндромов самых разных поджанров и сложности: от универсальных заумных палиндромов (разумно предположить, что такие палиндромы легко придумать на любом языке) до специфических магических квадратов. Надеемся, наша статья станет хорошим стартом для последующих работ, направленных как на более глубокое изучение карачаево-балкарских палиндромов, так и на включение в периметр исследований других форм комбинаторной литературы.

\section{Литература}

[1] Bonch-Osmolovskaya T. B. (2009). Introduction to Constrained Writing [Vvedenie v literaturu formalnykh ogranicheniy]. Bakhrakh-M, Samara.

[2] Bonch-Osmolovskaya T. B., Kislov V. M. (2014). Freedom through constraints: Anthology of Contemporary Texts Based on Rigid Formal Constraints [Svoboda ogranicheniya: Antologiya sovremennykh tekstov, osnovannykh na zhestkikh formalnykh ogranicheniyakh]. Novoe literaturnoe obozrenie, Moscow, p. 129.

[3] Guzeev Zh. M., Appoev A. K., Zhabelova L. Kh., Zhappuev A. A., Makhieva L. Kh., Musukov B. A., Otarov I. M., Ulakov M. Z. (2016). Modern Karachay-Balkar language [Sovremenniy karachaevo-balkarskiy yazyk]. Pechatniy dvor, Nalchik.

[4] Kuliev Kh. А. (1970). Time for a song [Жырны заманы]. Elbrus, Nalchik, p. 15.

[5] Tenishev E. R., Gochiyaeva S. A., Suyunchev Kh. I. (1989). Karachay-Balkar-Russian dictionary [Karachaevo-balkarsko-russkiy slovar]. Russkiy yazyk, Moscow.

\section{Интернет-ресурсы}

[6] https://www.ashtray.ru/main/texts/bonch_course/12.htm 
[7] https://code.energy/finding-magic-word-squares/

[8] http://www.corpus.tatar/ru

[9] http://www.elbrusoid.org/dictionary/

[10] http://www.elbrusoid.org/library/

[11] https://stihi.ru/2013/01/27/918

[12] https://tr.wikipedia.org/wiki/Palindrom 